\title{
Assessment of Self-Nanoemulsifying Drug Delivery System (SNEDDS) of Ethyl Acetate Fraction from Mangosteen (Garcinia mangostana L.,) Peels to Eschericia coli, Pseudomonas aeroginosa, and Proteus mirabilis
}

\author{
Liza Pratiwi* \\ Department of Pharmaceutical Technology, Faculty of Medical, Tanjungpura University, Pontianak, Kalimantan \\ Barat, Indonesia
}

\begin{abstract}
Mangosteen peels have antibacterial activity. SNEDDS has many advantages in developing a drug delivery system to increase the penetration of active compounds. The purpose of this study was to compare the effectiveness of the antibacterial SNEDDS of ethyl acetate fraction from mangosteen peels and ethyl acetate fraction of mangosteen peels without SNEDDS preparation as an antibacterial against Eschericia coli, Pseudomonas aeroginosa, and Proteus mirabilis, that cause diabetic ulcers. This research began with maceration. The thick ethanol extracts were continued and fractionation was carried out with ethyl acetate solvents then was formulated into SNEDDS. The measurement of the antibacterial activity with the bacterial growth inhibition parameters of SNEDDS preparations extracted from ethyl acetate fraction of mangosteen peels was compared with ethyl acetate fraction of mangosteen peels without SNEDDS preparation. Data were analyzed using independent sample T-Test. The results showed the SNEDDS preparation of ethyl acetate fraction from mangosteen peel had activity against both types of bacteria causing diabetic ulcers, but it had no activity against Proteus mirabilis. The results of statistical analysis showed that there were significant differences in the activity of SNEDDS ethyl acetate fraction of mangosteen peels and ethyl acetate fraction of mangosteen peels without SNEDDS in Eschericia coli and Pseudomonas aeruginosa.
\end{abstract}

Keywords: antibacterial; ethyl acetate fraction; mangosteen peels; SNEDDS

\section{INTRODUCTION}

Diabetic foot ulcer (DFU) is a complication of diabetes mellitus characterized with an open wound on the surface of the skin or mucous membrane and extensive dead tissue accompanied by bacterial invasion. At the Kitamura Care Specialist Clinic, among 800 diabetic patients, 470 of them suffered from DFU complications (Abidin et al., 2013). According to Sutjahjo (2013), the dominant infecting bacteria in diabetic patients with complications of gangrene were Pseudomonas, Staphylococci, Klebsiella, Bacillus and E. coli. The prevalence of DFU of $14.3 \%$ ended with death after a year of amputation and $37 \%$ would die 3 years after amputation (Lina and Sholihatul, 2016). Pseudomonas aeruginosa found in DFU patients was one of the bacteria with the highest percentage $(30,57 \%)$ (Manisha, 2012). E. coli bacteria was as much as 8,33\% (Sari and Apridamayanti, 2015). Proteus, Pseudomonas, Staphylococci, Klebsiella, Bacillus and E. coli bacteria were some of the bacteria that often infect diabetic wounds while the formation of gangrene gas was caused by Clostridium perfringens

*Corresponding author : Liza Pratiwi

Email : lyza_pratiwi@yahoo.com
(Mohammad et al., 2014). One of the therapies given to patients with DM with complications of diabetic ulcers is with antibiotics. Based on research by Sari and Apridamayanti (2015), DFU patients experienced resistance to several antibiotics and the alternative therapies of traditional medicine started to be able to suppress the occurrence of resistance. One of the plants that can potentially be used is mangosteen peels. Mangosteen is a plant that originates from the Southeast Asian regions, Indonesia, Malaysia, Thailand and Myanmar. It is a functional plant that is traditionally used as a medicine (Moongkandi et al., 2004; Weecharangsan et al., 2006). The mangosteen peels has been studied and is known contain of phenolic, tannin, flavonoid and xanthone compounds (Pedraza et al., 2008).

Mangosteen peels is a waste that has many benefits to be developed into drugs that have therapeutic effects. It has hypoglycemic activity (Taher et al., 2016), activity as an antimalarial (Tjahjani, 2017), antibacterial activity (Phitaktim et al, 2016). The mangosteen peels also has strong antioxidant activity (Tjahjani et al., 2014). Xanton is a polyphenolic compound that has semi-polar properties. The most xanthone derivatives and the best biological activity in mangosteen peels are 
$\alpha$-mangostin (Parveen et al., 1988); using ethyl acetate fraction solvents is expected to be able to attract $\alpha$-mangostin compounds. In an effort to maintain the stability of $\alpha$-mangostin and to increase comfort for patient, it needs to be made with pharmaceutical preparations. One of the pharmaceutical preparations is the selfnanoemulsifiying drug delivery system (SNEDDS). The advantages of conventional emulsions or lipids carriers were significantly reduced for their preparation and physical stability upon storage (Constantinides et al., 1996). SNEDDS have been described in the literatures as homogenous complex systems consisting of oils, surfactants, cosolvents and water, which are thermodynamically stable (Wang et al., 2009). When it is introduced into the body, it is rapidly dispersed to form droplets of approximately nano-size range $(<200$ $\mathrm{nm}$ ) (Gursoy et al., 2004). It can reduce the limitation of slow and incomplete dissolution of water-soluble drugs and facilitate the formation of isolated phases from which absorption might take place (Chakraborty et al., 2009). An effort in the prevention and control of resistance is the use of natural compounds that have the potential as antibacterial in applicative pharmaceutical preparations and proven effective in DFU wounds with bacterial infections. The aim of this study was to determine the antibacterial effectiveness of SNEDDS preparation ethyl acetate fraction from mangosteen peels compared with ethyl acetate fraction without SNEDDS, against diabetic foot ulcers. This research needs to be developed continuously to obtain effective mangosteen peels SNEDDS against $E$. coli, $P$. aeroginosa, and P.mirabilis bacteria in vitro. The success of the study has an impact on further development of the potential of the development of a pharmaceutical preparation.

\section{METHODOLOGY \\ Materials}

The dark purple peels were selected for the study were freshly from Central Java, Indonesia. The other materials are ethanol 70\% (Dwicentra), n-hexane (Merck), ethyl acetate (Merck), methanol (Merck), aquades (Dwicentra), VCO (Bagoes), PEG 400 (Bratachem), Tween 80 (Bratachem), Nutrient Agar (NA), Mueller-Hinton Agar (MHA), $\mathrm{NaCl}$ 0,9\% sterile were used.

\section{Methods}

Preparation of Plant Extract

One kg of powdered mangosteen peels was extracted via maceration for 72 hrs using ethanol
$70 \%$. Extracted samples were evaporated using waterbath until become thick extracts (Pratiwi et al., 2017).

\section{Preparation of Plant Fraction}

Some condensed ethanol extract was partitioned with n-hexane to obtain n-hexane soluble fractions and residues. Then, the residue was added with ethyl acetate to obtain the ethyl acetate fraction and residue. Furthermore, extracted soluble fraction of ethyl acetate fraction were collected and concentrated by rotary evaporator and a waterbath at $40 \pm 0,5^{\circ} \mathrm{C}$ to obtain a thick fraction (Pratiwi et al., 2017).

Preparation of SNEDDS ethyl acetate fraction Optimum SNEDDS formulated with a combination of surfactant, co-surfactant and oil, namely Tween 80, PEG 400 and VCO with a ratio of 4,98: 1,02: 1. Furthermore, ethyl acetate fraction $150 \mathrm{mg} / 5 \mathrm{~mL}$ SNEDDS was added. The mixture is conditioned in a waterbath at $40^{\circ} \mathrm{C}$ for 10 minutes. The process of dissolving the fraction in the carrier is maximized with a sonicator for 15 minutes.

\section{Antibacterial Effectiveness Test}

Sterilization of tools and materials was by covering the tools aluminum foil and cotton. They were put in an autoclave, and it was set at $121^{\circ} \mathrm{C}$ with a pressure of 15 psi (per square inch) (Radji, 2010).

\section{Nutrient Agar (NA) Media}

As much as 23 grams of nutrient was dissolved in $1000 \mathrm{~mL}$ of sterile aquadest and was then heated until all dissolved. In the heat state the solution was then put into erlenmeyer, followed by checking the $\mathrm{pH}$ of the media ranging from 6,8 \pm 0,2 . The media is then sterilized at $121^{\circ} \mathrm{C}$ autoclave for 15 minutes (Difco, 1977).

\section{Mueller-Hinton Agar (MHA) Media}

MHA media was made by dissolving media (38 grams) in $1 \mathrm{~L}$ of distilled water while being heated. It was then sterilized by autoclaving at 121 ${ }^{\circ} \mathrm{C}$ for 15 minutes (Difco, 1977).

\section{Bacterial Rejuvenation}

The pure culture of the test bacteria from the NA media was etched aseptically with ose needle on the sloping NA media. Scratching is done by zigzagging on the surface of the media. Then it was incubated at $37^{\circ} \mathrm{C}$ for 24 hours. 


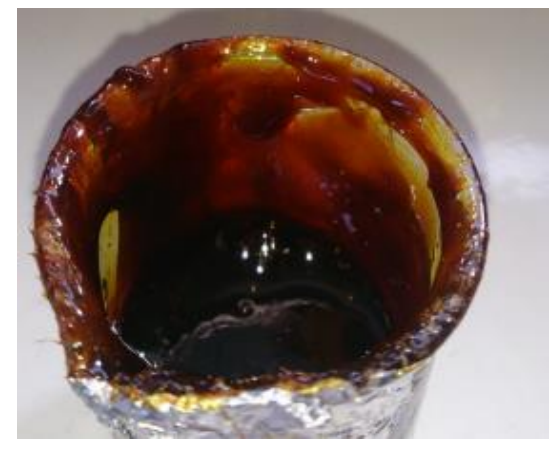

(1)

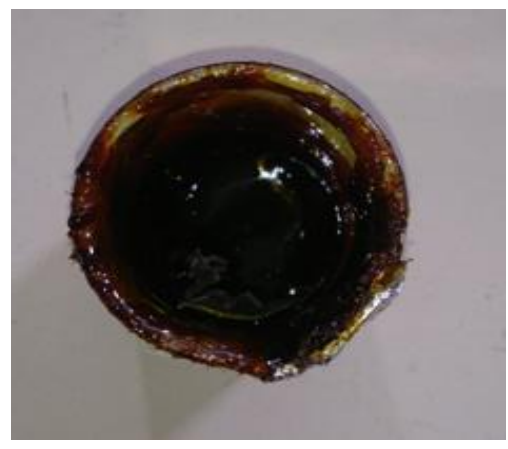

(2)

Figure 1. (1) Ethanol extract 70\% of mangosteen peels, (2) Ethyl acetate fraction of mangosteen peels

Suspension of Eschericia coli, Pseudomonas Aeroginosa, and Proteus mirabilis

Cultivating each bacterial suspension inoculated in a 24-hour rejuvenation medium was taken using an ose needle and was suspended into a tube containing $5 \mathrm{ml}$ of $0,9 \%$ sterile $\mathrm{NaCl}$ solution. The turbidity obtained was then compared to the standard Mc. Farland no. 0,5 which was equivalent to the amount of growth of $1 \times 108$ bacterial cells / $\mathrm{mL}$. After the equivalent, this suspension was used as a test bacterium (Radji , 2010).

\section{Test Solution Concentration}

Mangosteen peels has a MIC value of $200 \mu \mathrm{g}$ $/ \mathrm{mL}$ as an antimicrobial (Vishnu et al., 2010). Based on this, the test solution was made from SNEDDS of ethyl acetate fraction from mangosteen peels with a concentration of $200 \mu \mathrm{g} / \mathrm{mL}$.

\section{Testing of Antibacterial Activity}

This antibacterial power test was carried out using the disc diffusion method. Each test bacterium was inoculated on the MHA media. Paper discs $(6 \mathrm{~mm})$ were placed on the surface of the media and then on samples with varying concentrations of $200 \mu \mathrm{g} / \mathrm{mL}$. Dropping as much as $20 \mu \mathrm{L}$ of it in the well. Petri dishes were incubated at $37{ }^{\circ} \mathrm{C}$ for 24 hours, and the interpreted inhibitory zones formed were observed by analyzing at the clear area around the disc vertically and horizontally with measuring instrument (Sari et al., 2016).

Data Analysis of SNEDDS Assessment of Ethyl Acetate Fraction

The data were analyzed by independent sample T-Test to compare the significant values of SNEDDS ethyl acetate fraction of mangosteen peels and ethyl acetate fraction of mangosteen peels without SNEDDS.

\section{RESULT AND DISCUSSION SNEDDS Ethyl Acetate Fraction}

The sample used was fruit peels because extracts from mangosteen peels contained xanthone compounds, especially $\alpha$-mangostin and $\gamma$-mangostin which had pharmacological activity (Kapoor et al., 2009). The ethyl acetate fraction is able to dissolve in VCO due to the nature of this compound which is semi-polar, so it is easy to enter into the oil phase.

The mangosteen peels used were derived from ripe fruit peels because they have a higher total content of flavonoids and $\alpha$-mangostin compared to young mangosteen peels. The young mangosteen peels extract has a higher phenolic and tannin content compared to the fruit peels derived from mature mangosteen. The main compound in the ethyl acetate fraction of mangosteen peels is xanton, namely $\alpha$-mangostin. $\alpha$-mangostin is a polyphenol compound that has an $-\mathrm{OH}$ group on its side chain. The more amount of carbon in a compound, the more non-polar the compound is. According to Shafiq-un-Nabi et al. (2007), drug solubility in oil at SNEEDS is the most important component because it is related to the ability of SNEDDS to maintain dissolved drugs that are strongly influenced by drug solubility in the oil phase. Oil molecules that have a weak adhesion style will be easier to experience the bond stretching process compared to those with a stronger adhesion style. The stretching process is needed to form a configuration of oil molecules in order to capture one molecule of ethyl acetate fraction of mangosteen peels. In addition, viscosity also affects because it describes the density of oil molecules. The lower the viscosity of oil, the lower the density of itsmolecules. Tenuous oil molecules can easily interact with active compound molecules so that more active compound molecules that interact with oil molecules 


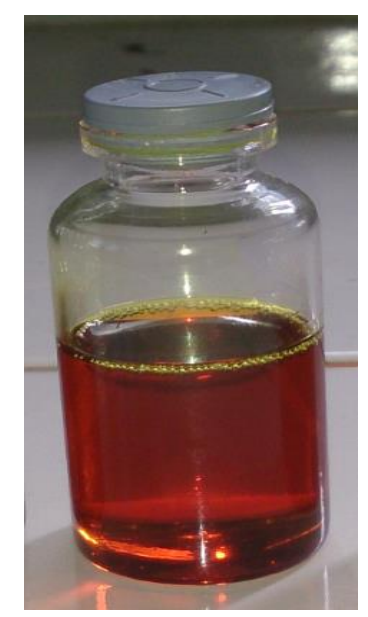

Figure 2. Optimum formula SNEDDS ethyl acetate fraction of mangosteen peels

cause larger active compounds to dissolve (Synco, 2006).

VCO is a high lauric oil containing saturated fatty acids, with glycerol to form a medium chain of triglycerides. Oils that have short and medium chain triglyceride chains are easier to form nanoemulsions compared to those have long chains (Date et al., 2010). Medium chain lipids can be more easily mixed with the water phase compared to long chain lipids, but they are also used in emulsions to facilitate the dissolution and encapsulation of hydrophilic drugs (Griffin et al., 2011). In a study with emulsions containing medium chain triglycerides namely soybean oil, Tween 80 surfactant, and PEG, the effects of osmotic swelling were found which led to increased drug release ability (Cunha et al., 1997).

\section{The effectiveness of SNEDDS of mangosteen peels against Eschericia coli, Pseudomonas aeroginosa, and Proteus mirabilis}

The data were obtained in the form of quantitative and qualitative data. Qualitative data was in the form of presence or absence of observable inhibition zones from ethyl acetate fraction with SNEDDS and ethyl acetate fraction without SNEDDS; quantitative data consisted of the amount of inhibition zones from ethyl acetate fraction with SNEDDS and ethyl acetate fraction without SNEDDS.

The results of the antibacterial activity of SNEDDS ethyl acetate fraction and non SNEDDS ethyl acetate fraction of mangosteen peels that have been carried out showed that there was inhibition of Eschericia coli growth which was characterized by the formation of inhibition zones around the wells which had been filled with test solutions showing that there was no bacterial growth. Based on Figure 3, it can be seen that SNEDDS ethyl acetate fraction has a greater inhibition zone than ethyl acetate fraction without preparation does. The results of the antibacterial activity test of SNEDDS ethyl acetate fraction produced inhibition zone diameters of $18,33 \mathrm{~mm} \pm$ 3,05 . Whereas, ethyl acetate fraction without preparations produced inhibition zone diameters of $13,22 \mathrm{~mm} \pm 3,65$. Data analysis with statistic using the independent sample T-Test test revealed the obtained p-value $0.024<0.05$ so that there is a difference between SNEDDS ethyl acetate fraction and ethyl acetate fraction without SNEDDS.

The results of the antibacterial activity of SNEDDS ethyl acetate fraction and ethyl acetate fraction of mangosteen peels without SNEDDS have been carried out showed that there was a growth inhibition of Pseudomonas aeroginosa which was characterized by the formation of inhibition zones around wells which had been filled with test solutions showing that there was no bacterial growth. The results of the antibacterial activity test of SNEDDS ethyl acetate fraction against Pseudomonas aeroginosa produced inhibition zone diameters of $12 \mathrm{~mm} \pm 1$. While ethyl acetate fraction without preparations produced inhibitory zone diameters of $11,83 \mathrm{~mm} \pm$ 4,64 . The Proteus mirabilis inhibition zone around the well was not formed, it was filled with a test solution which indicated that SNEDDS growth of SNEDDS ethyl acetate fraction bacteria and ethyl acetate fraction mangosteen peels has no antibacterial activity. Data analysis with statistic using the independent sample T-Test test revealed obtained p-value $0,048<0,05$ so that there is a difference between SNEDDS ethyl acetate fraction and ethyl acetate fraction without SNEDDS. 


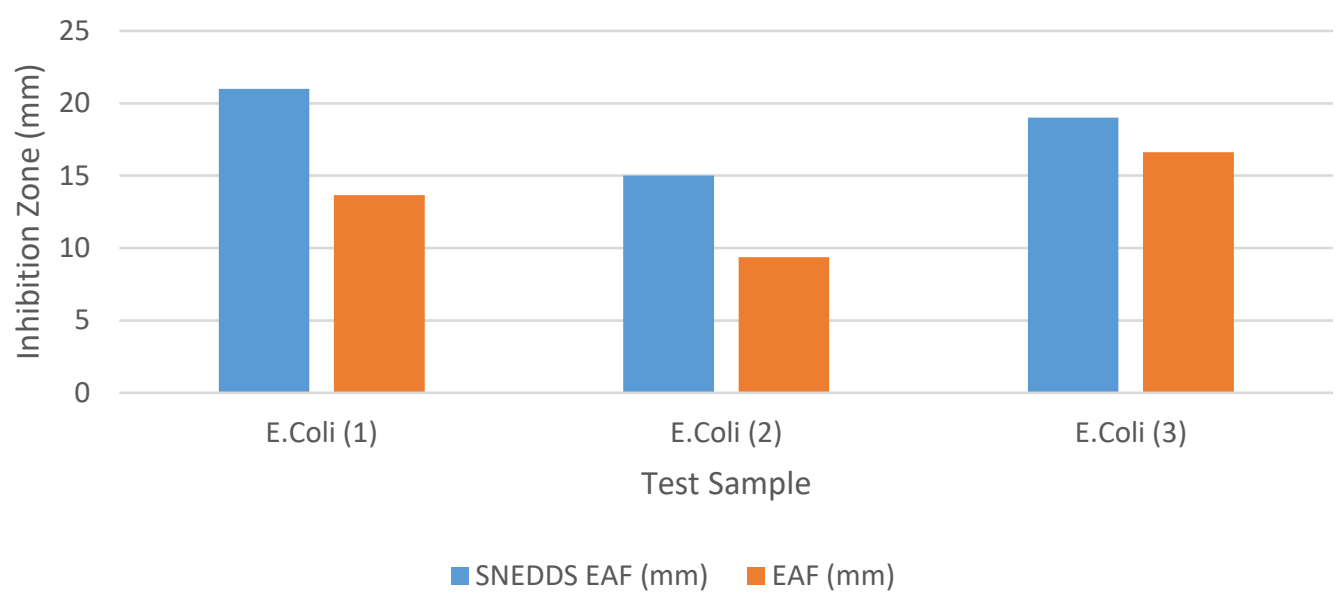

Figure 3. Inhibition zone SNEDDS ethyl acetate fraction and ethyl acetate fraction without SNEDDS to Eschericia coli

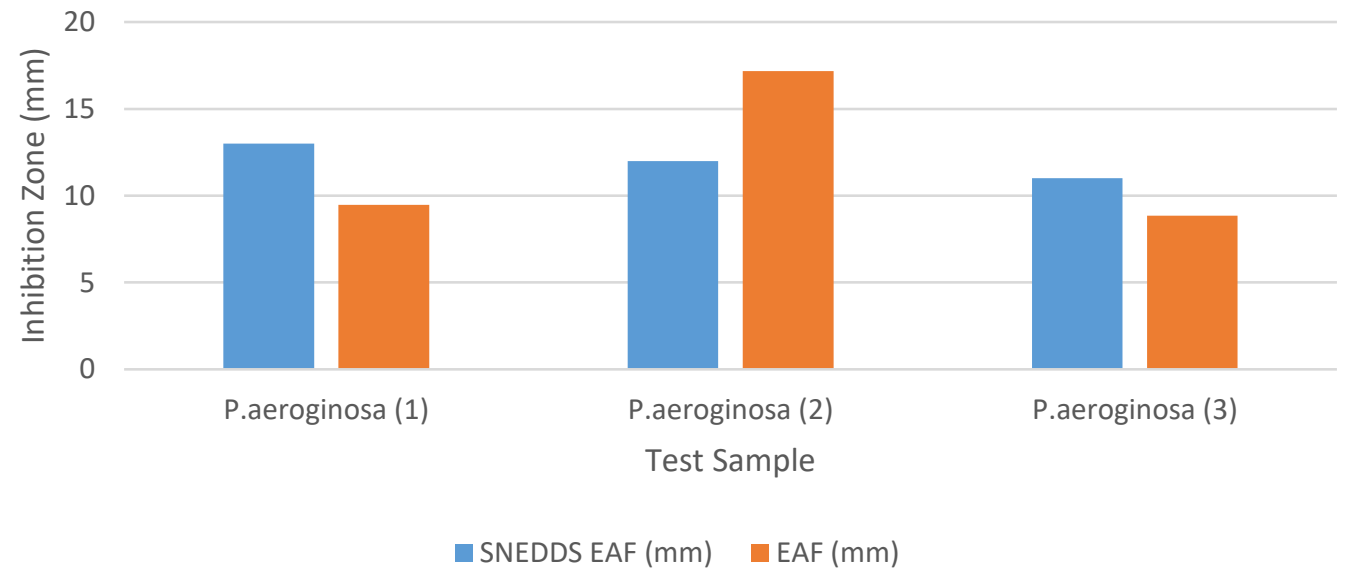

Figure 4. Inhibition zone SNEDDS ethyl acetate fraction and ethyl acetate fraction without SNEDDS to Pseudomonas aeroginosa

The antibacterial activity of SNEDDS ethyl acetate fraction and ethyl acetate fraction inhibiting the growth of Eschericia coli and Pseudomonas aeroginosa is thought to be the effect of the content of several secondary metabolites contained in the fraction. Antibacterial active ingredients can interfere with physiological processes and prevent the formation of bacterial cell components such as cell wall synthesis, cytoplasmic membrane protein synthesis and nucleic acid synthesis (Subandrio, 1995). Active ingredients that have high solubility in polar solvents will more easily penetrate the cell membrane phospholipid so that it disrupts the physiological functions of the bacteria more quickly and eventually the cells will die (Kneblock et al., 1989). Xanton is one form of flavonoids contained in the mangosteen peels which can denaturate proteins causing cell metabolic activity to stop (Trease et al., 1978). In addition, the mechanism of xanthone antimicrobial activity is thought to be due to the reaction of carbonyl groups in xanton with amino acid residues in cell membrane proteins, extracellular enzymes and cell wall proteins, which causes protein to lose its function (Nengah and Putera, 2010). Saponins, tannins, and flavonoids are compounds in plants that have antibacterial activity (Poeloengan and Praptiwi, 2010). Tannins are thought to be able to shrink bacterial cell walls so that they can interfere with cell permeability. Disruption of bacterial cell permeability causes the cell to be unable to carry out living activities so that its growth is inhibited or dies (Ajizah, 2004).

In this study, SNEDDS was formulated from Tween 80 as surfactant, PEG 400 as co-surfactant, and VCO as an oil phase. Tween 80 can be used as a penetration enhancer because Tween 80 is 


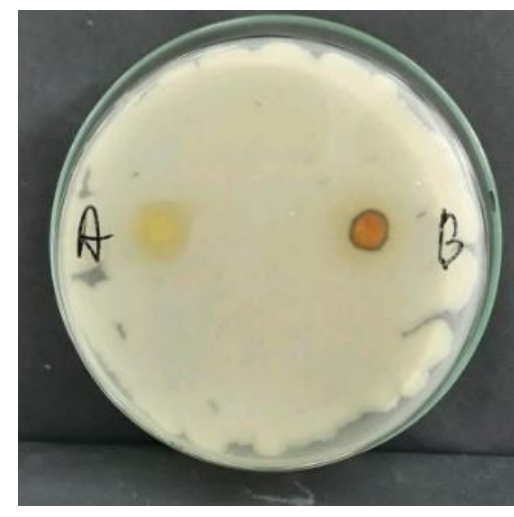

(1)

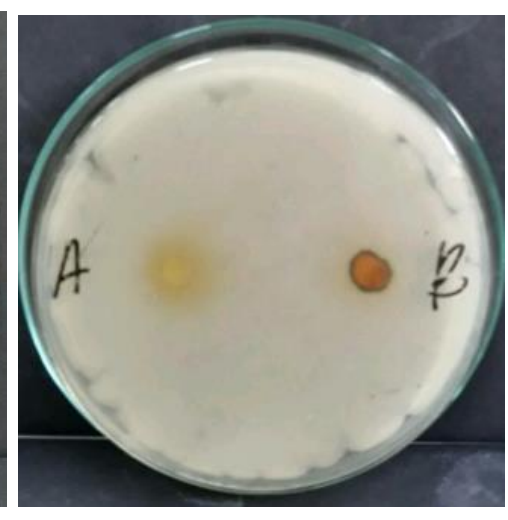

(2)

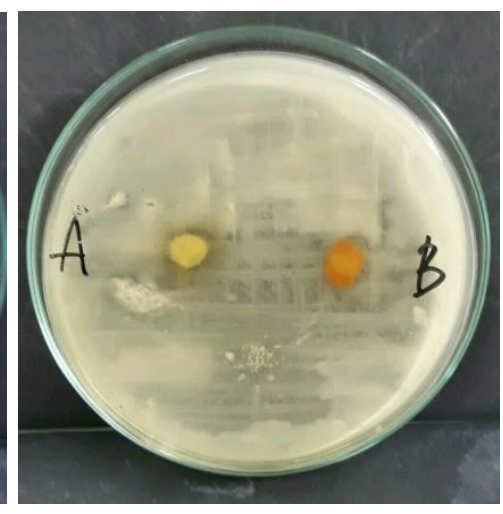

(3)

Note:

a. SNEDDS ethyl acetate fraction

b. Ethyl acetate fraction without SNEDDS

Figure 5. Effectivity SNEDDS ethyl acetate fraction and ethyl acetate fraction without SNEDDS to: (1) E.coli, (2) P.aeroginosa, dan (3) P.mirabilis

a surfactant that works by dissolving lipophilic compounds and dissolving the lipid layer in the stratum corneum. Ionic surfactants tend to cause damage to human skin and increase water loss in the skin because it can be held in the horn layer. Non ionic surfactants are safer to use because they do not cause skin damage, are more stable, and are practically not absorbed in the horn layer (Aiache, 1993). In fatty acids, the longer the chain of fatty acids will increase penetration. The fatty acids found in VCO are lauric acid. This can increase the penetration of compounds that are both hydrophilic and lipophilic. The mechanism is through interaction with lipids in the stratum corneum (Swarbrick and Boylan, 1995; Williams and Barry, 2004).

The strength of the extract in inhibiting the growth of test bacteria was classified according to inhibition zone diameter according to Monks et al. (2002) with the following criteria: inhibition zone diameters less than $7 \mathrm{~mm}$ were categorized as not having antibacterial activity; inhibition zone diameters 7-11,99 $\mathrm{mm}$ categorized as weak antibacterial activity. The inhibition zone 12-16,99 $\mathrm{mm}$ is categorized as medium antibacterial activity. Inhibition zone more than equal to $17 \mathrm{~mm}$ is categorized as strong antibacterial activity. Based on these criteria, the antibacterial activity of SNEDDS ethyl acetate fraction to Eschericia coli has very strong antibacterial activity while the antibacterial activity of ethyl acetate fraction to Eschericia coli has moderate antibacterial activity.
The antibacterial activity of SNEDDS ethyl acetate fraction and ethyl acetate fraction to Pseudomonas aeroginosa has moderate antibacterial activity.

\section{CONCLUSION}

SNEDDS ethyl acetate fraction has antibacterial activity against Eschericia coli with an inhibition zone of $18,33 \mathrm{~mm} \pm 3,05$ which is a strong antibacterial activity. Ethyl acetate fraction without SNEDDS has antibacterial activity against Eschericia coli with an inhibition zone of 13,22 mm $\pm 3,65$ which is of moderate antibacterial activity category. SNEDDS ethyl acetate fraction has antibacterial activity against Pseudomonas aeroginosa with inhibition zone of $12 \mathrm{~mm} \pm 1$. Ethyl acetate fraction without SNEDDS has antibacterial activity against Pseudomonas aeroginosa with inhibitory zones of $11,83 \mathrm{~mm} \pm 4,64$, which are both categorized as medium antibacterial activity.

\section{ACKNOWLEDGEMENT}

The authors would like to thank Pharmacy Departement, Faculty of Medicine Tanjungpura University.

\section{REFERENCES}

Abidin, K.R., Suriadi \& Adiningsih, B.S., 2013, 'Inhibiting Factors for Diabetic Foot Ulcer Wound Proliferation in Type II Diabetes Mellitus Patients in Pontianak Kitamura Clinic', Skripsi, Pontianak, Tanjungpura University. 
Aiache, J.M., 1982, 'Pharmacetics 2: Biopharmaceuticals', Airlangga University Press, Surabaya.

Ajizah, A., 2004, 'Sensitivity of Salmonella thypimurium to Psidium guajava L', Journal of Bioscientiae. 1, 31-38.

Cunha, A.S., Grossior, J.L., Puisieux, F. \& Seiller, M., 1997, 'Insulin in w/o/w multiple emulsions: preparation, characterization and determination of stability towards proteases in vitro', Journal of Microencapsulation. 14, 311-319.

Date, A.A., Desai, N., Dixit, R. \& Nagarsenker, M., 2010, 'Self-nanoemulsifying drug delivery systems: formulation insights, applications and advances', Nanomedicine. 5, 15951616.

Difco, 1977. Manual of dehydrated culture media and reagents for microbiology and clinical laboratory procedures (9th ed.), Detroit Michigan, Difco Laboratories.

Griffin, B. \& O'Driscoll, C., 2011, 'Opportunities and challenges for oral delivery of hydrophobic versus hydrophilic peptide and protein-like drugs using lipid-based technologies', Therapeutic Delivery. 2, 1633-1653.

Kapoor, V.K., Dureja, J. \& Chadha, R., 2009, 'Herbals in the control of ageing', Drug Discovery Today. 14, 992-998.

Lina, E. P. \& Sholihatul, M., 2016, 'Risk factors for chronic complications (diabetic legs) in Type 2 Diabetes Mellitus', The Indonesian Journal of Health Science. 7, 26-39.

Kneblock, K.A., Pauli, A., Iberl, B.,Weigland, H. \& Weis, N., 1989, 'Antibacterial and Antifungal Properties of Essential Oil Components', Journal of Essensial Oil Research. 1, 119-128.

Manisha, J., Mitesh, P.H., Nidhi, S.K., Modi, D.J. \& Vegad, M.M., 2012, 'Spectrum of microbial flora in diabetic foot ulcer and antibiotic sensitivity pattern in tertiary care hospital in Ahmedabad', National Journal of Medical Research. 3, 354-357.

Mohamad, N.A., Jusoh, N.A., Htike, Z.Z. \& Win, S.L., 2014, 'Bacteria identificaton from microscopic morphology: A review', International Journal on Soft Computing, Artificial Intelligence and Applications. 3, 112.

Moongkarndi, P., Kosem, N., Kaslungka, S., Luanratana, O., Pongpan, N. \& Neungton, N., 2004, 'Antiproliferation, antioxidation and induction of apoptosis by Garcinia mangostana (mangosteen) on SKBR3 human breast cancer cell line', Journal of Ethnopharmacology. 90, 161-166.
Monks, R., Clea Lerner, N., \& Amelia, H., 2001, 'Anticancer, antichemotatic and antimicrobial activities of marine sponges collected off the coast of Santa Catarina, southern Brazil', Journal of Experimental Marine and Ecology. 281, 1-12.

Nengah, K.P., 2010, 'Antibacterial Activity of Mangosteen (Garcinia Mangostana L.) Skin Extract and Its Active Compound Content', Jurnal Teknologi dan Industri Pangan. 21, 15.

Parveen, N. \& Khan, N.U., 1988, 'Two xanthones from Garcinia mangostana', Phytochemistry. 27, 3694-3696.

Pedraza-Chaverri, J., Cárdenas-Rodríguez, N., Orozco-Ibarra, M. \& Pérez-Rojas, J.M., 2008, 'Medicinal properties of mangosteen (Garcinia mangostana)', Food and Chemical Toxicology, 46, 3227-3239.

Phitaktim, S., Chomnawang, M., Sirichaiwetchakoon, K., Dunkhunthod, B., Hobbs, G, \& Eumkeb, G., 2016, 'Synergism and the mechanism of action of the combination of $\alpha$-mangostin isolated from Garcinia mangostana L. and oxacillin against an oxacillin-resistant Staphylococcus saprophyticus', BMC Microbiology. 16,195.

Poeloengan, M. \& Praptiwi., 2010, 'Antibacterial Activity Test for Mangosteen (Garcinia mangostana Linn) Peels Extract', Media Litbang Kesehatan. 10, 65-69.

Priya, V., Jainu, M., Mohan, S.K., Saraswati, P., \& Gopan, C.S., 2010, 'Antimicrobial activity of pericarp extract of garcinia mangostana linn', International Journal of Pharmaceutical Sciences and Research. 1, 278-281.

Radji, M., 2010, 'Microbiology Textbook: Pharmacy and Medical Student Guides', Jakarta: Medical Book Publishers, EGC.

Sari, R. \& Apridamayanti, P., 2015, 'Identification of ESBL-producing bacteria in patients with III and IV Wagner diabetic ulcer. DIPA Research Report. Pontianak: Tanjungpura University.

Shafiq-un-Nabi, S., Shakeel, F., Talegaonkar, S., Ali, J., Baboota, S., Ahuja, A., et al., 2007, 'Formulation development and optimization using nanoemulsion technique: a technical note', American Association of Pharmaceutical Scientists. 8, 12-17.

Sinko, J.P., 2006, 'Martin's Physical Pharmacy and Pharmaceutical Sciences', $5^{\text {th }}$ edition. Lippincott Williams and Wilkins, United State of America. 
Subandrio, W.K., 1995, Antimicrobial Chemotherapy, Antibiotics. MIPA Faculty, Indonesia University.

Swarbrick, J., \& Boylan, J.C., 1995, 'Encyclopedia of Pharmaceutical Technology', Marcel Dekker, New York.

Taher, M., Zakaria,T., Susanti, D. \& Zakaria, Z., 2016, 'Hypoglycaemic activity of ethanolic extract of Garcinia mangostana Linn in nomoglycaemic and streptozotocin-induced diabetic rats', Complementary and Alternative Medicine. 16, 135.

Trease, G.E. \& Evans, W.C., 1978, 'A Textbook of Pharmacognosy', $11^{\text {th }}$ Edition, London: Bailleire Tindal.
Tjahjani, S., Widowati, W., Khiong, K., Suhendra, A. \& Tjokropranoto, R., 2014, 'Antioxidant Properties of Garcinia Mangostana L (Mangosteen) Rind', Procedia Chemistry. 13, 198-203.

Weecharangsan, W., Opanasopit, P., Sukma, M., Ngawhirunpat, T., Sotanaphun, U. \& Siripong, P., 2006, 'Antioxidative and neuro protective activities of extracts from the fruit hull of mangosteen (Garcinia mangostana Linn.)', Journal Medical Principles and Practice. 15, 281-287.

Williams, A.C., \& Barry, B,W., 2004, 'Penetration enhancers', Advanced Drug Delivery Reviews. 56, 603-618. 